subsections that help readers keep track of the content without becoming smothered. The topics are wide-ranging and the facts seem accurate. Overall, it represents something radical in the best possible way, and for the best purpose.

Domagoj Kostanjšak

\title{
The Glocal World of Fairy Tales
}

Anna Katrina Gutierrez. 2017. Mixed Magic: Global-local Dialogues in Fairy Tales for Young Readers. Amsterdam/Philadelphia: John Benjamins Publishing Company. 230 pp. ISBN 978-90-272-0162-1.

DOI: 10.21066/carcl.libri.2017-06(02).0012

As the world becomes more connected through the process of globalisation, many aspects of one culture begin to take on certain traits of other cultures. The same thing happens in literature and the world of fairy tales. These processes are the main interest of Anna Katrina Gutierrez, professor at the Macquarie University in Australia. Using cognitive narratology, she compares several retellings of the same stories (for example, Beauty and the Beast) in order to see the influence of globalisation on the stories and their adaptations in local surroundings. Encompassing famous fairy tales, anime films, local stories and fables, her research examines how these narratives are shaped by the culture they belong to and how they are adapted to other cultures.

Gutierrez's monograph Mixed Magic: Global-local Dialogues in Fairy Tales for Young Readers, published by John Benjamins Publishing Company as the eighth instalment in the Children's Literature, Culture, and Cognition series, provides the author's contemplations and conclusions on the relationships between the East and West, and their representation in children's literature. Besides the introduction and the conclusion, the book has six chapters. Although each chapter has a different focus, they all deal with the same central issue: glocalisation, described as "a negotiation between domains considered global, local, East, or West that enriches realities and counters cultural uniformity" (xv). This common focus makes it easy for readers to immerse themselves into the fantasy world, and make connections and conclusions based on the presented information.

In order to set the framework for the research, the first chapter offers explanations of the most important terms used, such as fairy tales, cognitive narratology, globalisation, glocalisation, glocal, etc. Through these explanations, the reader is introduced to the main focus of the book - how global and local principles and beliefs intertwine and blend, thus creating glocal images in literature. Furthermore, these descriptions prepare the reader for further research presented in the second chapter with an analysis of several narratives (e.g. Angelfish by Laurence Yep, American Born Chinese by Gene Luen Yang, Tall Story by Candy Gourlay). In order to make the text more comprehensible, short summaries of the stories are provided, accompanied by explanations of their origin and meaning. With this approach and thorough analysis, it is easy for the reader to become aware that these stories are mutually connected through their basic premise, and that they share the same story script.

The next chapter deals with two famous fairy tales - Beauty and the Beast and Bluebeard, and their differences and similarities. It includes $19^{\text {th }}$ - and $20^{\text {th }}$-century retellings 
from the USA and the United Kingdom, based on the $18^{\text {th }}$-century notion of the Orient. The most prominent resemblance between the retellings of the two stories is their intertextuality which creates different concepts and perceptions of the East or West, depending on their place of origin. For this reason, the chapter contains several illustrations from the retellings, which, for example, show how European versions orientalised Bluebeard's palace to show his strangeness. The illustrations are very helpful as they show how this orientalisation was achieved and how it evolved over time.

The fourth chapter presents the world of anime films. After a short introduction to its history and main characteristics, Hayao Miyazaki's anime are presented as films set in glocal spaces - the main events happen in Western landscapes, seen through Eastern eyes. They celebrate Japanese traditions, connection with nature, and nostalgia, but at the same time they share some elements with fairy-tale scripts. Plot summaries of select anime, such as Kiki's Delivery Service (1989) and Porco Rosso (1992), are enriched with several illustrations, which show the beautiful world of anime films. They are very interesting to examine, and enable and encourage readers to do some research on their own.

The central characters of the next chapter are mermaids, creatures on the border between human and undersea worlds. Several Asian retellings mentioned in the book are based on The Little Mermaid by H.C. Andersen as well as the Japanese folktale Urashima Taro, for instance The Mermaid in the Whirlpool of the Pasig River by Severino Reyes. In the retellings, mermaids represent a desire for change and crossing the borders which constrain them. Through concise analyses, the stories are compared and their common features highlighted. One of them is the glocalisation of mermaids, achieved by setting traditional and well-known stories in a local (Asian) environment. As a result, these stories have glocal elements on two different levels: one is the undersea world, which is compared to its human counterpart, and the other is the place of origin of the story, which is contrasted with the place of its retelling.

The last chapter in the book gives the sense that it has come full circle because it returns to Beauty and the Beast, only this time the Beast is in focus. Besides this fairy tale, the chapter also mentions other stories which contain a character represented as a beast. Putting the beast at the centre of the analysis creates a new perspective, which stands in contrast to earlier research that mostly focused on female characters. This provides an insight into how beast characters are presented, how their nature is shaped, and what their (physical or mental) transformation represents.

Although each of these chapters deals with different types of characters, and even different types of media, they all consider the same central question of how globally known fairy tales, and their heroes, are transformed and adapted to local cultures. This process of glocalisation is demonstrated with several examples of stories gathered from different parts of the world, and accompanied by numerous illustrations. Additional effort was put into gathering the translations of stories from Japanese, German and Korean. The Filipino story included in the book was translated by the author, which also adds to the scope of the research.

Mixed Magic is an important contribution to the study of children's literature, and as such will be equally interesting to everyone involved in this field: experts and teachers, as well as students. It provides new insights into the world of children's stories, especially fairy 
tales, and the ways they transform and adapt to different cultures. It shows how the world becomes more connected with each day and how this is reflected in children's literature. It is important to recognise this sense of unity that glocalisation creates, and this can be done by simply reading fairy tales and thus becoming better acquainted with the cultures that surround us.

Josipa Hotovec

\section{Picturebooks and Problem Solving}

Jeanne White. 2017. Using Children's Literature to Teach Problem Solving in Math: Addressing the Standards for Mathematical Practice in K-5. Second Edition. New York and London: Routledge. 172 pp. ISBN 978-1-138-69470-5

DOI: 10.21066/carcl.libri.2017-06(02).0013

Introducing elementary students to mathematical word problems has always been a challenge for teachers, considering students' initial difficulties in reading, writing, counting, adding, and subtracting. One way teachers could facilitate this process and motivate students is to use children's literature as a context for word problems. The book Using Children's Literature to Teach Problem Solving in Math written by Jeanne White confronts this challenge and successfully connects mathematical concepts, children's literature, and classroom practice.

The focus of the book is on problem solving, which is usually described as students' capacity to respond to non-routine situations and find their own solutions. Since the author examines elementary school levels, children's literature which promotes mathematical ideas is presented as the context for problem solving. The book provides a list of about fifty picturebooks which could be used in mathematics education from kindergarten to the fifth grade.

Each chapter of the book is dedicated to one of the eight US Standards for Mathematical Practice. These are: "Make sense of problems and persevere in solving them", "Reason abstractly and quantitatively", "Construct viable arguments and critique the reasoning of others", "Model with mathematics", "Use appropriate tools strategically", "Attend to precision", "Look for and make use of structure", and "Look for and express regularity in repeated reasoning". In each of these chapters, the author presents 6 to 8 picturebooks which may be used to encourage problem solving and meet the particular Standards requirement. With each presented picturebook, the author suggests a detailed teaching scenario for communicating with students about mathematical ideas from picturebooks and using problem solving in discussions with students. These ideas are related not only to the textual aspect of picturebooks, but also to illustrations, and are meant to encourage students' creativity and imagination.

Since mathematics, literature and classroom practice meet in this book and make a solid unity, it provides three important reading aspects: the mathematical aspect, the literary aspect, and the didactical aspect. Each aspect interacts with the other two because of the interdisciplinary nature of teaching mathematics and teaching in general.

The mathematical aspect of the book refers to selected mathematical topics, activities, and ideas presented in various picturebooks. Most of the suggested picturebooks deal 